\title{
Food patterns, flour fortification, and intakes of calcium and vitamin D: a longitudinal study of Danish adults
}

\author{
M Osler, B L Heitmann
}

Department of Social Medicine and Psychosocial Health, Institute of Public Health, University of Copenhagen,

Copenhagen, Denmark M Osler

Danish Epidemiology Science Centre at the Institute of Preventive Medicine, Copenhagen Hospital Corporation, Copenhagen Municipal Hospital, Copenhagen, Denmark

B L Heitmann

The Copenhagen County Centre of Preventive Medicine, Department of Medicine C, Glostrup University Hospital, Glostrup, Denmark

M Osler

B L Heitmann

Correspondence to:

Dr M Osler, Department of Social Medicine and

Psycosocial Health,

University of Copenhagen,

Blegdamsvej 3, $2200 \mathrm{~N}$,

Denmark.

Accepted for publication 5 June 1997

\begin{abstract}
Study objective-Deficiencies in calcium and vitamin $D$ intakes are involved in the aetiology of osteoporosis, and health authorities recommend that the population consume a diet providing sufficient calcium and vitamin D. However, in 1987 the Danish Government withdrew a mandatory fortification of flour with calcium. This study examines intakes of calcium and vitamin $D$ over time, in relation to food patterns, recommendations, and legislation.

Design-Food and nutrient intakes were measured by a short food frequency questionnaire (FFQ) and a thorough diet history interview, in 1987/88, and again six years later.

Setting-Copenhagen County, Denmark. Participants-329 men and women, aged 35-65 years at first examination in 1987/88. Results-At both examinations the nonenriched median intakes of calcium in men as well as women were above the recommended $600 \mathrm{mg} /$ day. However, apparently the fortification of flour supplied up to $30 \%$ of the total calcium intake, and without the mandatory fortification, the percentage of adults with intakes below this recommendation increased from $6 \%$ to $22 \%$. This group of subjects consumed cheese, milk, and oatmeal less often than those who had calcium intakes over 600 mg/day. During the study period the median intakes of vitamin $D$, which were well below the recommended $5 \mu \mathrm{g} / \mathrm{day}$, did not change significantly. Associations between foods and vitamin $D$ intakes were, in general, weak and insignificant, except for a positive association with fish intake. Conclusions-Data on calcium intakes suggest that the decision to stop the mandatory fortification of flour with calcium may have been premature. The short FFQ may be used for a rough classification of people in relation to their calcium intake, while this method seems insufficient for ranking vitamin $D$ intakes.
\end{abstract}

(F Epidemiol Community Health 1998;52:161-165)

With more than 10000 cases each year, and an increasing incidence, hip fractures represent a major health problem in Denmark, as well as in many other westernised countries, osteoporosis being the most common cause. The composition of the diet plays an important part for bone mineral content. ${ }^{1}$ For instance, it is probable that a diet, deficient in calcium during childhood, reduces the peak bone mass achieved between 20-30 years of age. Furthermore, it has been shown that among adult postmenopausal women, an adequate dietary intake of calcium and vitamin $\mathrm{D}$ can minimise the amount of bone mineral loss, and thereby the subsequent risk of bone fractures. ${ }^{1}$ Therefore, health authorities have recommended that populations, and especially women, consume a diet providing sufficient calcium and vitamin $\mathrm{D}$, for example, high intakes of dairy products and fish with a high fat content. Furthermore, to prevent calcium deficiency in the Danish population, flour has been fortified with calcium, $200 \mathrm{mg} / 100 \mathrm{~g}$ wheat flour and 400 $\mathrm{mg} / 100 \mathrm{~g}$ ryeflour, since 1954, and until 1987 when the mandatory fortification was stopped. The possible effect of this policy on calcium intakes in a Danish population has not yet been investigated. Similary, in Britain, where calcium has been added to flour since 1942, the fortification policy has been questioned. ${ }^{2}$

Today it is generally accepted that compliance with dietary recommendations may be better, and more easy to monitor, if recommendations are formulated in terms of foods rather than nutrients. Changes in food intake are often measured by a food frequency questionnaire (FFQ). Hence, from a public health point of view, it is important to know if food intake, measured by short FFQs, can be used for monitoring nutrient intakes. A number of FFQs, which can be used particularly for estimating the usual calcium intake, have been developed..$^{3-6}$ However, to our knowledge, there are no studies describing how food intake, measured by a short FFQ, associate with calcium and vitamin $\mathrm{D}$ intakes in the general population.

Therefore, this study aims at evaluating intakes of calcium with and without the mandatory calcium enrichment of flour, and examining how food intake patterns, estimated from a short FFQ, associate with intakes of calcium and vitamin D over time, and in relation to dietary recommendations.

\section{Methods}

SUBJECTS

The study included 552 Danish citizens aged $35,45,55$, and 65 years. This group was an age and sex stratified random sample of the population in the western part of Copenhagen County selected from the Central Person Register. All subjects were invited to a general 
health examination. Of the 552 subjects invited, 435 agreed to participate in this study and to give a diet history interview. Nonparticipation has been described earlier. ${ }^{7}$

The study was a part of the Danish MONICA project and was carried out in collaboration with the Copenhagen County Centre of Preventive Medicine. The examination (GEN-MONICA) was carried out from December 1987 to November 1988. After six years, 511 of the 552 subjects originally sampled were alive, and could be invited to a follow up examination, and $365(71 \%)$ attended. Of these, 329 had also participated in the GEN-MONICA study. The 106 and 36 subjects who did not participate in the follow up or baseline examinations, respectively, had the same distribution by sex, age, body mass, and energy intake as the 329 subjects who attended both examinations (all $\mathrm{p}>0.20$ ). The present analysis includes these 329 subjects. This sample is considered to be representative of the total sample. The 163 men and 166 women of the sample were equally distributed across the four age groups and had a mean BMI of 25.2 and $24.6 \mathrm{~kg} / \mathrm{m}^{2}$, respectively.

FOOD FREQUENCY DATA

The method of data collection was the same at the two examinations.

An extensive questionnaire on sociodemographic variables, lifestyle, and health was completed before the general health examination, and the dietary history interview. This self administered questionnaire included questions about how often 26 food items were consumed. A few food groups were added because they were not mutally exclusive, therefore the present analysis is based on 24 food groups. The alternatives used in the frequency scale were as follows: never, once a month or less, 2 to 3 times a month, once a week, 2 to 3 times a week, once a day, 2 to 3 times a day, and 4 times or more daily. In the statistical calculations, the scale alternatives have been converted into weekly frequencies. The same short FFQ has been used by the WHO for monitoring food consumption patterns in the MONICA project, ${ }^{8}$ and has furthermore been validated as a part of the present study. ${ }^{9}$ This validation showed, that the mean food intake measured by a diet history interview increased with increasing frequency category of the FFQ, indicating that this questionnaire was able to identify levels of food intake correctly. Furthermore, those who reported a less frequent intake by the FFQ in 1993/94 compared with $1987 / 88$ also had lower mean daily intakes according to the diet history information. Thus the short FFQ may be used to monitor changes in food patterns at a group level.

DIET HISTORY INTERVIEW

In $1987 / 88$, and six years later, the same trained dietitian interviewed all the subjects about their habitual diet by the diet history method. The diet was assessed, based on information for the previous month, and average daily intakes were calculated from this information. Meal patterns, dishes, and foods were explored by interview using a detailed precoded interview form. Quantities were explored by the use of food models, photo series, cups, and measures. This instrument has been validated earlier. ${ }^{7}$ Nutrient calculations were carried out with the DANKOST program, which is derived from the Danish Food Composition Tables. This database included 835 food items in 1988, but in 1991 it was extended and now comprises 1250 food items.

The intakes of calcium and vitamin $\mathrm{D}$ were estimated from the diet history reports. The intake of calcium from 1987/88 was calculated using food composition tables based on values both with, and without, enrichment of flour. As nutrient intakes are strongly associated with energy intake, relative measures, for example, amounts per MJ consumed, have been calculated. Table 1 gives the distribution of the intakes of energy, calcium, and vitamin $\mathrm{D}$ at both examinations.

\section{STATISTICAL METHODS}

The intakes of calcium and vitamin $\mathrm{D}$ were approximately normally distributed. Differences in mean values were examined using a $t$ test. The FFQ data were measured on an ordinal scale, and differences in food intake between groups of subjects complying, or not complying, with recommended daily intakes of calcium $(>600 \mathrm{mg})$ and vitamin $\mathrm{D}(>5 \mu \mathrm{g})$ were examined using a non-parametric Wilcoxon-Mann-Whitney test. Stepwise multiple linear regression analyses were used to select the foods in the FFQ groups that best predicted intakes of calcium and vitamin $\mathrm{D}$, assessed from the diet history. The dependent variables included the absolute and relative intakes of calcium and vitamin $\mathrm{D}$, calculated from the diet history interview. The 24 foods listed in table 2 were entered into the equation. The criterion applied for adding new variables in to the equation was that each new variable had to improve the variance explained by the model with at least $1.5 \%$. All models were screened for colinearity between independent variables by variance inflation factors. This excercise showed that colinearity was not a problem. The analyses were carried out for the whole group, for men and women separately, and furthermore for the women stratified by age older and younger than 51 years. The sex and age specific models differed only slightly, and therefore the results will not be commented on in the text.

Individual changes in food intake measured by the FFQ method were estimated by subtracting the 1993/94 score value from the $1987 / 88$ value. A negative value indicates a more frequent food intake, zero values mean no change, and a positive value indicates a less frequent food intake. Changes in absolute nutrient intake, reflected by the diet history method, were assessed in the same manner. A stepwise regression analysis was used to identify those changes in the intake of the 24 individual food items that best predicted changes in intakes of calcium and vitamin $\mathrm{D}$. 
Table 1 Median, 25th and 75th percentiles of energy, and the absolute and relative intakes of calcium and vitamin D in Danish men and women estimated from diet history interview in 1987/88 and 1993/94. Differences in intakes at baseline and follow up given ( $p$ values)

\begin{tabular}{|c|c|c|c|c|}
\hline & \multicolumn{4}{|l|}{ Percentiles } \\
\hline & 25 th & 50th & 75 th & $p$ values \\
\hline \multicolumn{5}{|c|}{ Energy (MJ/day) } \\
\hline \multicolumn{5}{|c|}{$\begin{array}{l}\text { Total } \\
\text { ting }\end{array}$} \\
\hline $1987 / 88$ & 6.8 & 8.3 & 10.4 & \multirow[t]{2}{*}{0.07} \\
\hline $1993 / 94$ & 7.2 & 8.5 & 10.8 & \\
\hline \multicolumn{5}{|l|}{ Men } \\
\hline $1987 / 88$ & 8.2 & 10.2 & 11.9 & \multirow[t]{2}{*}{0.24} \\
\hline $1993 / 94$ & 8.6 & 10.5 & 11.9 & \\
\hline \multicolumn{5}{|l|}{ Women } \\
\hline $1987 / 88$ & 5.9 & 7.2 & 8.3 & \multirow[t]{2}{*}{$<0.01$} \\
\hline $1993 / 94$ & 6.4 & 7.5 & 8.5 & \\
\hline \multicolumn{5}{|c|}{ Calcium (mg/day) } \\
\hline \multicolumn{5}{|c|}{ Total } \\
\hline $1987 / 88 \mathrm{f}$ & $879(113)$ & $1215(146)$ & $1594(176)$ & \multirow{3}{*}{$\begin{array}{l}<0.01(<0.01)^{\star} \\
0.23(0.87)\end{array}$} \\
\hline $1987 / 88$ & $625(79)$ & $838(105)$ & $1187(133)$ & \\
\hline $1993 / 94$ & $647(80)$ & $855(101)$ & $1147(121)$ & \\
\hline \multicolumn{5}{|l|}{ Men } \\
\hline $1987 / 88 \mathrm{f}$ & $977(107)$ & $1344(137)$ & $1810(163)$ & \multirow{3}{*}{$\begin{array}{l}<0.01(<0.01)^{\star} \\
0.27(0.23)\end{array}$} \\
\hline $1987 / 88$ & $668(70)$ & $942(95)$ & $1257(118)$ & \\
\hline $1993 / 94$ & $710(75)$ & $944(96)$ & 1263 (117) & \\
\hline \multicolumn{5}{|l|}{ Women } \\
\hline $1987 / 88 \mathrm{f}$ & $825(126)$ & $1068(154)$ & 1415 (189) & \multirow{3}{*}{$\begin{array}{l}<0.01(<0.01)^{\star} \\
0.60(0.20)\end{array}$} \\
\hline $1987 / 88$ & $612(87)$ & 793 (119) & 1079 (143) & \\
\hline $1993 / 94$ & $616(88)$ & $800(107)$ & 1068 (137) & \\
\hline \multicolumn{5}{|c|}{ Vitamin D ( $\mu \mathrm{g} /$ day $)$} \\
\hline Total & & & & \multirow{3}{*}{$0.19(0.17)$} \\
\hline $1987 / 88$ & $1.7(2.1)$ & $2.6(3.0)$ & $4.1(4.5)$ & \\
\hline $1993 / 94$ & $1.7(2.0)$ & $2.6(2.9)$ & $4.5(5.4)$ & \\
\hline \multicolumn{5}{|l|}{ Men } \\
\hline $1987 / 88$ & $2.2(2.3)$ & $3.1(3.3)$ & $5.3(4.7)$ & \multirow[t]{2}{*}{$0.61(0.49)$} \\
\hline & $1.8(1.8)$ & $2.9(2.8)$ & $6.0(5.7)$ & \\
\hline \multicolumn{5}{|l|}{ Women } \\
\hline $1987 / 88$ & $1.4(2.0)$ & $1.9(2.9)$ & $3.1(4.1)$ & \multirow[t]{2}{*}{$0.13(0.23)$} \\
\hline $1993 / 94$ & $1.6(2.1)$ & $2.3(3.1)$ & $4.0(5.3)$ & \\
\hline
\end{tabular}

$\mathrm{f}=$ Fortified. Relative intakes (in $\mathrm{mg}$ or $\mu \mathrm{g} / \mathrm{MJ}$ ) in parentheses. ${ }^{\star}, t$ Test fortified versus non-fortified values.

Table 2 Average food intake frequencies in men and women complying, or non-complying, with recommended guidelines for calcium intake

\begin{tabular}{|c|c|c|c|c|}
\hline & \multicolumn{4}{|c|}{ Mean food intake frequency (times per week) } \\
\hline & $\begin{array}{l}1987 / 88 \\
\text { Non-compliers }(n=74)\end{array}$ & $\begin{array}{l}\text { Compliers } \\
(n=255)\end{array}$ & $\begin{array}{l}1993 / 94 \\
\text { Non-compliers }(n=52)\end{array}$ & $\begin{array}{l}\text { Compliers } \\
(n=277)\end{array}$ \\
\hline \multicolumn{5}{|l|}{ Fats and dairy foods } \\
\hline Animal fats & & & 9.4 & 8.0 \\
\hline Vegetable $\mathrm{m}$ & 6.0 & 6.7 & 5.0 & 5.4 \\
\hline Low-fat m & 4.2 & 3.6 & 5.0 & 3.6 \\
\hline Cheese & 5.0 & $7.7 \S$ & 5.0 & $6.8^{\star}$ \\
\hline Milk, yoghurt & 2.6 & $8.3 \S$ & 2.1 & $7.5^{\star}$ \\
\hline \multicolumn{5}{|l|}{ Meats, eggs, fish } \\
\hline Eggs & 1.7 & $2.3 \$$ & 1.7 & 1.8 \\
\hline Fish & 0.7 & 1.0 & 1.0 & 1.1 \\
\hline Meat & 5.5 & 4.9 & 5.0 & 4.9 \\
\hline Sausages & 5.0 & 5.2 & 4.4 & 4.9 \\
\hline \multicolumn{5}{|l|}{ Fruits and vegetables } \\
\hline Fruit & 5.0 & 5.9 & 5.0 & 5.8 \\
\hline Juice & 1.8 & 1.9 & 3.0 & 1.9 \\
\hline Vegetables & 7.7 & 6.2 & 4.6 & 5.8 \\
\hline \multicolumn{5}{|c|}{ Breads, cereals, starches } \\
\hline Coarse bread & 3.6 & 4.6 & 4.3 & 4.7 \\
\hline Dark ryebread & 7.3 & 8.7 & 8.0 & 9.0 \\
\hline White bread & 3.8 & 3.6 & 3.9 & 3.2 \\
\hline White ryebread & 3.2 & 3.1 & 3.7 & 3.7 \\
\hline Oatmeal & 0.5 & $1.4 \rrbracket$ & 0.7 & $2.1^{\star}$ \\
\hline Pasta & 0.4 & 0.5 & 0.8 & 0.9 \\
\hline Potatoes & 4.2 & 4.3 & 4.1 & 3.9 \\
\hline Rice & 0.9 & 0.9 & 0.9 & 1.0 \\
\hline \multicolumn{5}{|l|}{ Baked goods, sweets } \\
\hline Cakes, biscuits & 2.0 & 2.1 & 1.9 & 2.6 \\
\hline Candy, chocolate & 1.6 & 1.5 & 2.5 & 1.7 \\
\hline Jam, honey & & 3.3 & 3.1 & 3.1 \\
\hline Ice cream, soda & 1.5 & 1.7 & 2.1 & 1.6 \\
\hline
\end{tabular}

Animal fats=butter, traditional margarine, lard; $\mathrm{m}=$ margarine; soda $=$ carbonated beverages.

${ }^{*} \mathrm{p}<0.01$ : Wilcoxon-Mann-Whitney test compliers with a daily calium intake of $600 \mathrm{mg} / \mathrm{day}$ or more, versus non-compliers with daily calcium intake of less than $600 \mathrm{mg} /$ day. 
Table 3 Stepwise multiple regression analysis (regression coefficients (b), standard error (SEM), 95\% confidence intervals (95\%CI), and cumulative variance $\left(r^{2}\right)$ ) of associations between intake frequency of food items and relative daily calcium intake (mg/MF) in 329 Danish men and women

\begin{tabular}{lrccc}
\hline Food items & \multicolumn{1}{c}{ SEM } & \multicolumn{1}{l}{$95 \% C I$} & $r^{2}$ \\
\hline 1987/88 & 0.03 & 0.03 & $0.25,0.36^{\star \star}$ & 0.21 \\
$\quad$ Milk, yogurt & -0.26 & 0.06 & $-0.37,-0.15^{\star \star}$ & 0.27 \\
Sausages & -0.15 & 0.06 & $-0.26,-0.03^{\star}$ & 0.31 \\
Candy, chocolate & 0.19 & 0.07 & $0.07,0.32^{\star}$ & 0.33 \\
Vegetables & -0.18 & 0.08 & $-0.33,-0.03^{\star}$ & 0.35 \\
Meat & -0.19 & 0.08 & $-0.34,-0.03^{\star}$ & 0.37 \\
Fruit & 0.33 & 0.04 & $0.28,0.43^{\star \star}$ & 0.33 \\
1993/94 & -0.25 & 0.06 & $-0.37,-0.14^{\star \star}$ & 0.40 \\
$\quad$ Milk, yogurt & & & & \\
Sausages & & & &
\end{tabular}

Table 4 Stepwise multiple regression analysis (regression coefficients (b), standard error (SEM), 95\% confidence intervals (95\%CI), and cumulative variance $\left(r^{2}\right)$ ) of associations between change in intake frequency of food items and change in calcium intake (mg/day) from 1987/88 to 1993/94 in 329 Danish men and women

\begin{tabular}{lrlrl}
\hline Food items & \multicolumn{1}{c}{ S } & SEM & \multicolumn{1}{l}{$95 \% C I$} & $r^{2}$ \\
\hline Milk, yogurt & 11.2 & 4.8 & $1.6,20.9^{\star \star}$ & 0.09 \\
Oatmeal & 23.0 & 7.1 & $8.9,37.1^{\star \star}$ & 0.15 \\
Vegetables & -11.6 & 3.7 & $-17.6,-3.1^{\star \star}$ & 0.19 \\
Cheese & 10.3 & 4.6 & $2.5,20.8^{\star \star}$ & 0.22 \\
\hline
\end{tabular}

${ }^{\star} \mathrm{p}<0.01$.

\section{Results}

CALCIUM INTAKE

Table 1 shows that absolute intakes of calcium were highest in men, while relative intakes $(\mathrm{mg} / \mathrm{MJ})$ were highest in women. Calculating calcium intake from food composition tables, with and without flour fortification, showed that the enrichment of flour resulted in an average increase in calcium intake of about $30 \%$, or approximately $300 \mathrm{mg} /$ day.

Assuming all flour consumed in 1987/88 had been enriched by calcium, only nine men $(6 \%)$ and 12 women $(7 \%)$ would have had intakes lower than the recommended $600 \mathrm{mg} /$ day. Without the enrichment, 34 men $(21 \%)$ and 40 women $(24 \%)$ would have had intakes below recommendations. Compared with those complying with recommendations, these subjects consumed cheese, milk, eggs, and oatmeal less often (table 2). The multivariate analysis showed that, in $1987 / 88,37 \%$ of the variation in calcium intake (both enriched and nonenriched data) was explained by the consumption frequency of six food items (milk, sausages, candy, vegetables, meat, and fruit) (table 3).

In 1993/94, the intake of calcium was below recommendations for 19 men (12\%) and 33 women $(20 \%)$, and as at baseline this group of subjects consumed cheese, milk, and oatmeal less frequently than those with daily calcium intakes over $600 \mathrm{mg}$ (table 2). In the multivariate analysis, $40 \%$ of the variation in the relative intake of calcium was explained by milk and sausages (table 3 ).

The non-enriched mean intakes of calcium did not change significantly during the study period (table 1). In the regression analysis individual changes in the consumption frequency of milk, oatmeal, cheese, and vegetables were significant predictors of changes in calcium intake during the study period (table 4).

\section{KEY POINTS}

- Removal of calcium fortification from flour in Denmark in 1987 increased the fraction of adults with intakes below recommendations from $6 \%$ to $22 \%$.

- Subjects with low calcium intakes consumed cheese, milk, and oatmeal less often than those complying with recommendations.

- Nearly $80 \%$ of adult Danes had vitamin $\mathrm{D}$ intakes below the recommended 5 $\mu \mathrm{g} / \mathrm{day}$, and they consumed fish less often than those complying with recommendations.

- Milk consumption measured by a short food frequency questionnaire explained about $30 \%$ of the variation in calcium intake.

\section{VITAMIN D INTAKE}

Table 1 shows that the median intake of vitamin $\mathrm{D}$ was well below the recommeded 5 $\mu \mathrm{g} /$ day. The absolute values were lower in women than in men, while there were no sex differences in the relative intakes. One hundred and twenty one men (74\%) and 152 women $(92 \%)$, had intakes lower than the recommended $5 \mu \mathrm{g} /$ day. Fish were consumed significantly less often in subjects with insufficient intakes, than in subjects with sufficient intakes $(p<0.01)$. The multivariate analyses showed that none of the food items from the food frequency questionnaire were significantly related to vitamin $\mathrm{D}$ intake.

As at baseline, the $116(71 \%)$ men and 143 $(86 \%)$ women with low vitamin $\mathrm{D}$ intakes at follow up consumed fish less often, compared with those with sufficient vitamin D intakes. In the multivariate analysis the consumption of fish now explained about $4 \%$ of the total explainable variation in vitamin $\mathrm{D}$.

The average intake of vitamin $\mathrm{D}$ did not change significantly during the study period (table 1), and in multivariate analysis none of the changes in consumption the frequency, of any foods, were predictors of individual changes in vitamin $\mathrm{D}$ intake.

\section{Discussion}

This study showed that although calcium intake is adequate for most adults, the fortification of flour may have supplied up to $30 \%$ of the total calcium intake, and without this mandatory fortification the percentage of adults with intakes below recommended level increased from $6 \%$ to $22 \%$. In Denmark, fortification was introduced based on an assumption, unsupported by actual evidence, that certain subgroups of the population consumed insufficient calcium. ${ }^{10}$ The first nationwide food survey in Denmark, in 1985, estimated that, in general, calcium intake was adequate, which in addition to the adverse effects of a high calcium intake such as inhibition of the absorption of other minerals, ${ }^{11}$ led to the questioning of the relevance of the enrichment. ${ }^{12}$ Consequently, the mandatory fortification of 
flour was stopped in January 1987. However, in Britain, where the fortification policy has also been questioned, ${ }^{2}$ Hackett et $a l,{ }^{13}$ and later Moynihan et $a l,{ }^{14}$ were able to show that calcium fortification of flour supplied some $15 \%$ of the total calcium intakes in the diet of English adolescents, and the recommendation from the DHSS, to stop the mandatory flour fortification, has never been implemented. ${ }^{15} \mathrm{We}$ showed that the removal of the mandatory fortification of flour in Denmark more than doubled the fraction of adults with intakes below recommendations, and suggest that the removal of calcium fortification from flour may have been premature. To our knowledge no studies have evaluated the possible beneficial, or adverse, effects of calcium fortification. In this context, ecological studies would show that the hip fracture incidence has been steadily increasing since $1980 .{ }^{16}$ Those may suggest that calcium fortification of flour has had no effect on bone mineralisation in those who were at middle age in the $1950 \mathrm{~s}$. On the other hand, it may be speculated that it is the calcium intake in adolescence and young adulthood that determine bone mineral content later in life. As a consequence, the effect of withdrawal of the mandatory calcium fortification on the incidence of hip fractures, should not be apparent before the 2030s.

The associations between food intake measured by the FFQ, and calcium intake, assessed by diet history, showed that the known most important sources of calcium in the Danish such as milk and cheese were included in most predictive models. Intake of sausages was negatively associated with calcium intake, indicating that a frequent consumption of sausages may serve as an indicator of a food intake pattern low in calcium.

As in this study, other dietary studies of Danish adults, have shown that the intake of vitamin $\mathrm{D}$ is well below the national recommendations, with no specific groups at risk. ${ }^{11}$ There were only small changes in the intake of vitamin $\mathrm{D}$ over the six year period between $1987 / 88$ and $1993 / 93$. We find it probable that the stability in intake of vitamin D over time, as shown by this study, reflects a truly stable intake, and does not depend on methodological issues, as the data were collected (a) at the same place (b) by use of the same questionnaire, and (c) by the same dietitian. All associations between vitamin $\mathrm{D}$ intake and food items, were weak. Vitamin D is only present in foods of animal origin. The content is highest in fat fish $(>3 \mu \mathrm{g} / 100 \mathrm{~g})$, and in full fat dairy products and meat $(<1 \mu \mathrm{g} / 100 \mathrm{~g})$. The FFQ did not specify type of fish, dairy or meat products and, hence, grouped these foods in very broad and non-specific categories. This may have obliterated the between person variation for the specific foods high in vitamin $\mathrm{D}$, and may explain the relatively weak associations found for these food groups. Other explanations include the possibility that the food composition tables are less valid for vitamin $\mathrm{D}$ than for other nutrients such as calcium, or that vitamin $\mathrm{D}$ intake is reflected by the intake of foods high in fat, which may be more liable to be underreported. ${ }^{17}$ On the other hand the stronger, and significant association between fish and vitamin D intake found in 1993/94 could represent a shift towards eating more fat fish, related to health information about the benefits of fish oil. However, it may also be because of chance, as many statistical tests were carried out.

Based on the present analyses, it is concluded that the average intake of calcium and vitamin $\mathrm{D}$ did not change significantly during the study period. However, a recalculation of the data using food databases with and without flour fortification showed, that without this enrichment the percentage of adults with intakes below recommended levels increased from $6 \%$ to $22 \%$. The decision to stop the mandatory calcium fortification in Denmark may thus have been premature. We further conclude that the short FFQ may be used for a rough classification of people as to their calcium intakes, while this method seems insufficient for ranking vitamin $\mathrm{D}$ intakes.

This work was done in collaboration with the Research Department of Human Nutrition of the Royal Veterinary and Agricultural University, Denmark.

Funding: the project was supported by grants from the Danish Agricultural and Veterinary and Danish Medical Councils and the Danish Health Insurance Foundation.

Conflicts of interest: none. 1 Michaelsen KF, Astrup A, Mosekilde L, Richelsen B, Schroll M, Sørensen O H. The role of nutrition in the pre-
vention of osteoporosis. Ugeskr Laeger 1994;156:958-62.

2 Department of Health and Social Security. Nutritional aspects of bread and flour. Report on health and social subjects. Report by the Committee on Medical Aspects of Food Policy. London:HM Stationary Office, 1981.

3 Cummings SR, Block G, McHenry K, Baron RB. Evaluation of two food frequency methods of measuring dietary calcium intake. Am $\mathscr{f}$ Epidemiol 1987;126:796-802.

4 Angus RM, Sambrook PN, Pocock NA, Eisman JA. A simple method for assessing calcium intake in Caucasian women. F Am Diet Assoc 1989;89:209-14.

5 Brown JL, Griebler R. Reliability of a short and long version of the Block food frequency form for assessing changes in calcium intake. F Am Diet Assoc 1993;93:784-9.

6 Wilson P, Horwath C. Validation of a short food frequency questionnaire for assessment of dietary calcium intake in questionnaire for assessment of dietary

7 Heitmann BL. The influence of fatness, weight change slimHeitmann BL. The influence of fatness, weight change slim-
ming history and other lifestyle variables on diet reporting in Danish men and women aged 35-65 years. Int F Obes 1993;17:329-36.

8 Boeing M, Wahrendorf J, Heinemann L, et al. Results from a comparative dietary assessment in Europe. Comparison of dietary information derived from concurrently applied frequency questionnaires and quantitative measures. Eur $\mathcal{F}$ Clin Nutr 1989;43:367-77.

9 Osler M, Heitmann BL. The validity of a short food frequency questionnaire and its ability to measure changes in food intake. Int $\mathcal{F}$ Epidemiol 1996;25:1023-9.

10 Helms P. Dietary surveys in rural Denmark though 50 years. Copenhagen:Danish Household Council, 1987.

11 Deehr MS, Dallal GE, Smith KT, Taulbee JD, DawsonHughes B. Effects of different calcium sources on iron absorption in postmenopausal women. Am f Clin Nutr 1990;53:95-9.

12 Haraldsdottier J, Holm L, Jensen JH, Møller A. Danish dietary habits 1985. Main results. Copenhagen: National Food Agency, 1986

13 Hackett AF, Rugg-Gunn AJ, Allinson M, Robinson CJ, Apppleton DR, Eastoe JE. The importance of fortification of flour with calcium and the sources of calcium in the diet of 375 English adolescents. Br F Nutr 1984;51:193-7.

4 Moynihan P, Adamson A, Rugg-Gunn A, Appleton DR, Butler T. Dietary sources of calcium and the contribution of flour fortification to total calcium intake in diets of Northumbrian adolescents. Br f Nutr 1996;75:495-505.

15 Richardson DP. Food fortification. Proc Nutr Soc 1990;49: 39-50.

16 Schrøder HM, Andreassen MD, Villadsen I, Sørensen JG, Erlandsen MS. Increasing age-specific incidence of hip fractures in a Danish municipality. Dan Med Bull 1995;42: fractures

17 Heitmann BL, Lissner L. Dietary underreporting by obese individuals - is it specific or non-specific? BMF 1995;311: 